\title{
Clinical training in medical students during preclinical years in the skill lab
}

This article was published in the following Dove Press journal:

Advances in Medical Education and Practice

2 March 2017

Number of times this article has been viewed

\author{
Namrata Upadhayay \\ Department of Physiology, Gandaki \\ Medical College Teaching Hospital and \\ Research Center, Kaski, Nepal
}

Background: In Nepal, medical education is a high-stakes and stressful course. To enhance learning and minimize students' stress, the conventional method has been replaced by integrated, student-centered learning. As an approach to train effectively, colleges have started establishing skill labs.

Objectives: To evaluate the effectiveness of clinical skill training on exam performance as compared with the conventional teaching practice. Further, to assess the perceptions of students of the importance of skill lab training in college.

Method: Twenty students were randomly selected to participate in this cross-sectional study. On the internal examination, students showed skills on manikins, and examiners evaluated them. A sample question in the exam was "To perform cardiopulmonary resuscitation (CPR) on half body human manikin." On completion of the exam, opinions were collected from the students via a predesigned self-administered questionnaire. The questionnaire included questions regarding skill lab use and its benefits to them in developing their skills, with a few questions related to the exam pattern. The responses were expressed in frequencies.

Results: We found that all (20/20) students performed CPR with confidence and without hesitation on the manikin. The practical examination performance (marks) was categorized as excellent $(7 / 20)$, good $(8 / 20)$, average $(3 / 20)$, and poor $(2 / 20)$. The pass percentage after skill training was increased by $25 \%$ as compared with conventional teaching practice. The majority of the students $(17 / 20)$ mentioned that skill is better learned by doing than by observing others' performance or watching videos. A few students (6/20) said skills are better learned by observing the real disease state. They mentioned that skill lab is the better choice for learning major skills such as catheterization, opening vein, auscultation of heart sounds, and endotracheal intubation.

Conclusion: Students are confident and showed better exam performance after basic clinical skills training in the lab. They perceived skill lab training as a better teaching method for the preclinical students.

Keywords: skill lab, preclinical years, practical examination, innovative learning

\section{Introduction}

The duration of the medical course (Bachelor of Medicine and Bachelor of Surgery [MBBS]) in Nepal is five years and six months. Students spend the first two years studying applied basic medical sciences along with community medicine and professional skills with stress on multidisciplinary and multiprofessional education. In the remaining years, they study clinical disciplines with rotatory internship in the last year.

Acquisition of clinical knowledge is necessary, but implementing them in a real scenario is the most crucial aspect of medical training. Skill is to be performed by hand and should be executed in an accurate way without error. Implementing skills 
with success in a primary setup, hospital, or in the community is a goal/job for medical personnel. Nowadays, many medical colleges have an established skill lab according to the "Accreditation Standards for MBBS" laid down by the Nepal Medical Council. In 2008, a skill lab was established at the Institute of Medicine. ${ }^{1}$ Similarly, our institute, Gandaki Medical College, established a well-equipped skill lab in 2015 as per the criteria of the Nepal Medical Council.

The introduction of a skill lab for students in the early phase of their clinical training might help students in learning the basic clinical techniques. It can be introduced in preclinical years, as they are not directly exposed to patients. Moreover, there are certain skills that cannot be practiced in real-life situations. Nor can some skills be performed in adult healthy individuals. These include cardiopulmonary resuscitation, nasogastric tube insertion, and endotracheal intubation. Therefore, using simulators, manikins, medical equipment, and models to mimic the clinical situation can help students learn better. It has been observed that in the practical examinations of the first and second years of MBBS, students are hesitant and find it difficult to perform clinical examinations on the patients or subjects provided. This might be because students are hindered by certain ethics and emotional component (exam stress, anxiety, fear of making mistakes that may harm to patients or subjects etc.) from performing better in the exam. Therefore, our objective was to find out how skill lab training as compared with conventional teaching methods helps students to perform better in the practical examination. The other objective is to gauge students' perceptions on skill lab establishment and its training in medical college. Toward this end, we conducted a study in real examination time to evaluate the efficacy of imparting training skills in students in terms of their exam performance during the preclinical years.

\section{Method}

In a cross-sectional study performed on 20 second-year MBBS students, their exam performance in terms of pass percentage was compared both after training with the conventional teaching method and after training in the skill lab. They were examined for their skills in the practical examination.

The students were categorized as very poor, poor, average, good, and excellent, and on completion of their exams, were asked for their feedback, in a structured questionnaire, on the "exam performance" and "exam pattern" used in the Physiology department.

The questionnaire also included some questions on the use of the skill lab in the medical college and its benefits to the students.
Ethical statements: Ethical clearance was obtained from the Institutional Ethical Committee of Gandaki Medical College. All the participants in the study confirmed that their participation was voluntary and signed the informed written consent which included permission for publication of their images in this paper.

\section{Study outline}

1. Sample size selection: The total of 40 second-year students were divided into two batches of 20 each for the examinations. From each batch, 10 students were randomly selected, making a total of 20 students included in the study.

2. Conventional teaching method: A practical demonstration was first given by the teachers, and the students, who comprised the listeners, were given time to observe the teachers' performance. They were also provided a

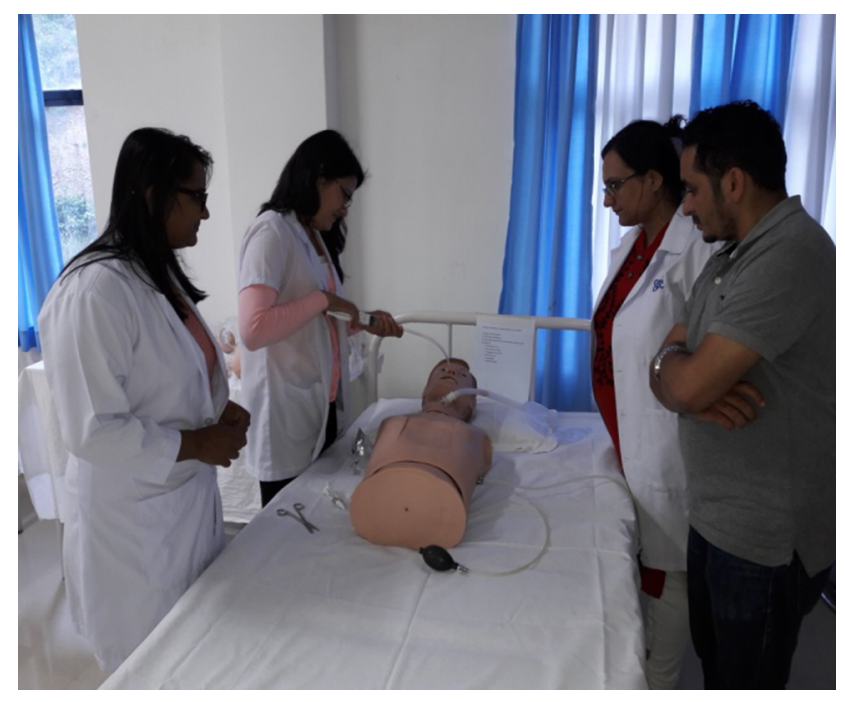

Figure I Endotracheal intubation and nasogastric feeding model.

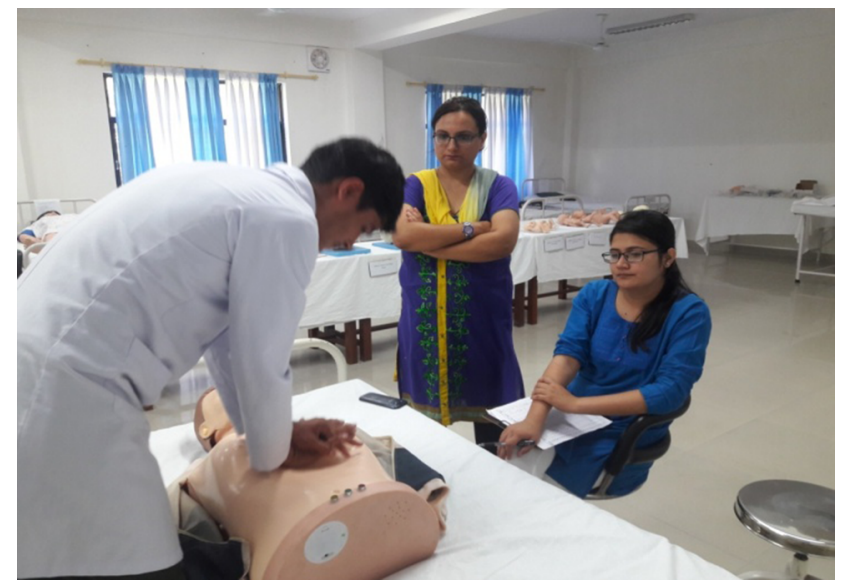

Figure 2 Demonstration of cardiopulmonary resuscitation in half body human manikin. 
chance to ask questions when they found the procedure difficult to understand, and their doubts were clarified immediately. Next, they were made to answer questions in the log book, which they submitted to the department for correction and evaluation. In the practical examination, they were asked to perform the procedure that they had been taught in the practical class, and were allotted marks. Students securing fifty and above out of hundred marks were considered successful in the examination. Their performance was kept confidential and compared with their performance in another exam that followed. In this other practical exam, for which they had received training in the skill lab, marks were awarded for performance and a grade was assigned.

3. Demonstration of skills in the skill lab: A few months before the term examination, practical skills were demonstrated to students in the skill lab in the Department of Physiology, Gandaki Medical College, Lekhnath, Nepal. For example, among the demonstrations were cardiopulmonary resuscitation in a manikin, blood sample collection from venous blood, electrocardiographic recording and its interpretation, and auscultation of heart and breath sounds.

4. Practice of students: After the demonstration of different skills, students were allowed to practice in the skill lab under the guidance of the tutor. They practiced the skill techniques on different manikins and models in the laboratory (Figures 1 and 3).

5. Evaluation of students: A few months later, an internal practical assessment of the students was conducted. This involved performing certain tasks on manikins and models. Their skills were evaluated by examiners with the help of a checklist. Following this, a viva was conducted,

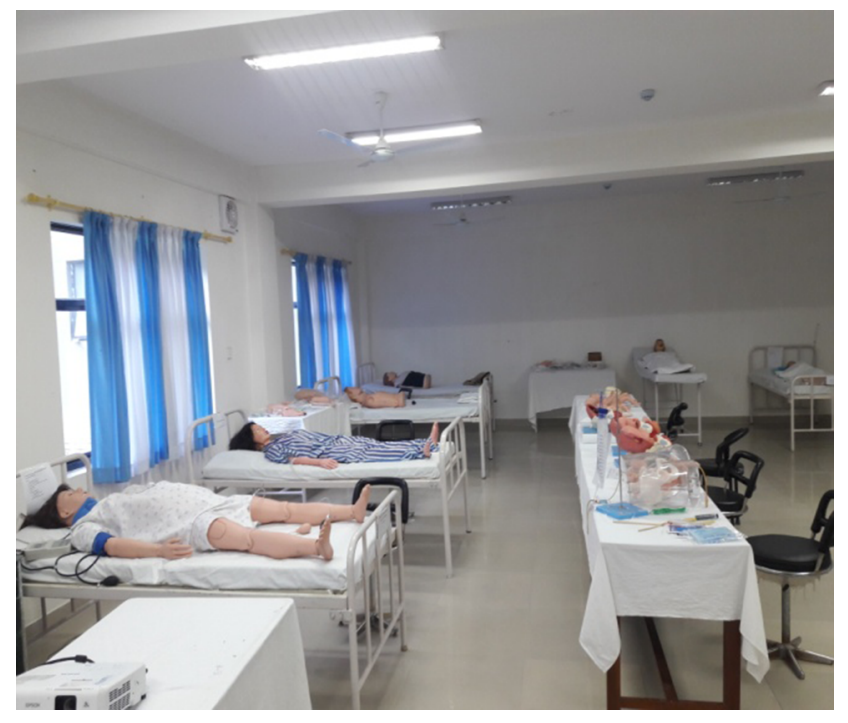

Figure 3 Skill Lab at basic block of Gandaki Medical College, Lekhnath, Kaski. in which they were asked questions related to the subject matter. Students were given marks based on their skill performance and on the viva.

The students who performed well and with confidence, with due consideration of all the crucial and minor steps of the checklist (skills steps), were rated as excellent performers; those who performed major steps of skills were ranked as good, who missed few steps but performed the skills were ranked as average and who did not performed any steps of skills were ranked as very poor performers, accordingly. The allotment of marks on the viva also contributed to their performance and helped classify them as excellent, good, average, poor, or very poor performers.

6. Administration of questionnaire: At the completion of the practical examination, students were asked for their opinions on the skill lab and exam performance via a predesigned self-administered questionnaire.

\section{Details of skills to perform in the examination and students evaluation}

Students were asked to perform and show their clinical techniques in some exam questions.

1. Sample questions in the practical exam: Practical questions administered to the students in the examination included the following:

a. "Perform cardiopulmonary resuscitation on half body human manikin" (Figure 2).

b. "Auscultate the precordium and record the heart sounds of the given subject. Interpret the result".

2. Expertise observation during examination: Based on the checklist for the given questions and their practical performance, experts (examiners) on that particular skills assessed the students with marks.

\section{Details of the questionnaire administered}

At the completion of the practical examination, students were asked for their opinions via a predesigned self-administered questionnaire.

1. It included questions regarding skill lab implementation, its use at medical college, and its benefits.

2. Some questions were about the practical exam pattern adopted by the Physiology department. The exam pattern in the department included around ten spotters (one spotter for two minutes of two marks) and long (for 40 minutes) and short (20 minutes) practicals with open 
viva (sets of questions with maximum opportunity for the alternative questions).

3. A few questions were related to students' exam performance after basic clinical training in the lab.

4. The questionnaire also included a few open-ended questions that sought suggestions for improving the examination system in the department.

The Likert scale from "strongly agree to strongly disagree" in all structured questionnaires was used. Suggestions that were given in response to the open-ended questions were classified according to themes and concepts, and the frequency was then calculated using Microsoft Excel 2007 (Microsoft Corporation, Redmond, WA, USA). Every student's performance in the two examinations (before and after the skill lab training) was documented, and the frequency of students who passed was recorded from both.

\section{Results}

Twenty students were examined for their skills in the practical examination and were categorized as very poor, poor, average, good, and excellent students. Later, they gave their feedback on the "exam performance" and the "exam pattern" used in the Physiology department using a self-designed structured questionnaire.

\section{Comparison of exam performance in two practical examinations}

We found that the students' exam performance had improved, as $25 \%$ more students passed after receiving basic clinical skills as compared with the conventional teaching method.

1. Exam performance by the conventional teaching method: Of the 20 students, 13 (65\%) passed the examination, and the highest mark obtained was $64.4 \%$.

2. Exam performance after the skill lab practice: Of the 20 students, $18(90 \%)$ passed the examination, and the highest mark obtained was $76.23 \%$.

\section{Evaluation of students by examiners}

We found that all the 20 students performed cardiopulmonary resuscitation on the manikin confidently and without hesitation (Figure 2). In other clinical skills, 13 students (auscultation of heart sounds, clinical examination of respiratory system, etc.) and in procedural skills (ECG interpretation and blood sample collection and estimating hemoglobin concentration, calculating bleeding and clotting time, calculating differential leukocyte count etc) 18 students performed better in the examination. Similarly, other skills were evaluated as very poor, poor, average, good, and excellent. On average, the overall performance of the students in the practical examination was categorized as excellent $(7 / 20)$, good $(8 / 20)$, average $(3 / 20)$, and poor $(2 / 20)$ in the internal examination (Figure 4$)$.

\section{Results on student perception of importance of skill lab in learning clinical skills}

The majority of students (17/20) perceived that skill is better learned by doing than by observing others performing it or by watching videos. A few students (6/20) said that having models of different clinical conditions/diseases does not help them to learn better; instead, they need to observe the real clinical scenario to get a better picture or understanding of it.

\section{Views of students on the exam pattern in the Physiology department}

The majority of them (18/20) strongly agreed that Physiology is an interesting subject to study. The exam pattern (spotters, long and short practicals, and open viva) adopted by the department is good. They suggested that more clinical training be included in some invasive procedures, for example, drawing venous blood from the arm and ECG interpretation in the graph.

\section{Views of students on adopting skill lab and its benefits in medical college}

1. All the students mentioned that the skill lab is the better choice for learning some major skills such as catheterization, opening vein and collecting blood samples, hearing different breath sounds in models/dummies, endotracheal intubation, genital examination, etc, than doing them directly in the patients.

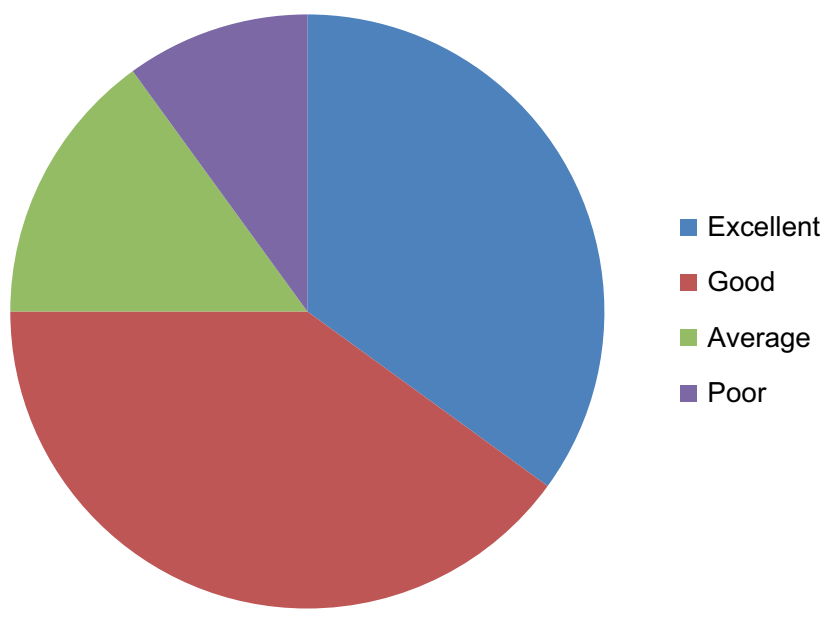

Figure 4 Percentage distribution of students in the practical examination, n-20. 
2. They $(10 / 20)$ mentioned that skill lab is a necessity and that it should be in regular use for students, interns, and professional doctors. They mentioned that continuous use of skill lab helps to sharpen the skills of doctors too.

3. They $(15 / 20)$ suggested rotation of students to skill lab and to clinical posting in the hospital, emphasizing that this rotation would help them better understand clinical conditions.

\section{Discussion}

Use of the skill lab for imparting basic clinical skills has been included in the curriculum of Institute of Medicine, Tribhuvan University. ${ }^{2}$ It has been stated that students should learn clinical skills (rectal, ear drum, and breast examinations, auscultation of different types of heart and breath sounds) and procedural skills (cardiopulmonary resuscitation, intubation, ECG interpretation, catheterization, blood sample collection, etc.).

We conducted this study to ascertain the effectiveness (exam performance) of clinical training in the second year of MBBS when students appear for the practical examination. Evaluation was based on the performance of the students during the practical examination and during the viva. Also, we gathered opinions from the students to ascertain their perceptions on the exam pattern used in the Physiology department and the benefits of adopting the skill lab in the medical college.

In our study, students obtained better marks in the practical examination on what they have been trained in the skill lab, and this is similar to the result of another study. ${ }^{3}$ The percentage of students who passed increased by $25 \%$ in the later examination (after the basic clinical skills) as compared with the baseline examination performance (the conventional method). In one study, internal medicine students who were trained in communication and basic clinical skills were found to perform better in the examination as compared with the control group of students. ${ }^{4}$ They mentioned that structured training is superior to the traditional bedside courses, despite the fact that the students were taught in larger groups and that more skills were covered in the same period of time.

We found that the majority of the students agreed that skill is better learned by doing than by observing others performing it or by watching videos. They mentioned that they were able to picture what they had learned from the theory in the skill lab. This implies that the skill lab is helping students to bridge the gap between their knowledge and practice. Factual knowledge is theoretical, eg, learning the adverse effects of penicillin, types of muscles in the body, or the definition of the drunken gait. Procedural knowledge is the practical part of medicine, eg, how to draw blood, or conduct a clinical examination on a patient. ${ }^{5}$ Thus, the skill lab seems to be a link between factual and procedural knowledge. In a study, $97 \%$ of students' perceived early introduction of clinical skills learning in the preclinical years (first clinical exposure-third year students) helped them to prepare for the clinical years and was a favorable teaching strategy. ${ }^{6}$

In our study, few students perceived that the learning would be better if they observed the real disease state rather than learning clinical disease in the models. It seems true that correlating the observed clinical condition with the real clinical scenario can enhance student learning. That could be the reason for their suggestion to incorporate skill lab training followed by clinical posting in the hospital for the preclinical students. A clinical skill lab makes theoretical teaching "come alive". This might help them to achieve continuing professional development and integrated learning of basic and clinical knowledge. However, it is true that the clinical picture presented by the patients will be different than that presented by the speechless dummies/models. Therefore, rotation of students in the skill lab and in hospital posting should be done in an alternate manner. Thus, the skill lab could be an additional way of learning clinical skills that will sensitize the students, but it cannot replace the old conventional bedside teaching practice.

We found that students taking Physiology as an interesting subject to study and that the exam pattern adopted by the department was good. All the students mentioned that skill lab is the better choice for learning major skills such as catheterization, opening vein and collecting blood samples, hearing different breath sounds in models/dummies, endotracheal intubation, genital examination etc compared with doing them directly in the patients. Nevertheless, students suggested that they required more clinical training in some invasive procedures such as for drawing venous blood and making ECG interpretations. This indicates that they need more practice to sharpen their skills. Hence, introducing the skill lab in the preclinical years would be a better choice to help students learn and sharpen their skills. As the emotional component (pain, tiredness, or hungry) in dummies/models is absent, one can practice on it for a long time until one masters it. This is not possible in patients, and ethics does not allow for it. Therefore, the skill lab could be a better platform for those who are beginners as well as for those who are in internship. In one study, it was found that compared with a combination of traditional skills training and internships, a curriculum improvement involving integration and intensification of skills 
training with skills assessment yielded higher basic clinical skills competence. ${ }^{8}$ Hence, clinical training should be introduced in the early phase with more exposure and with a better practicing environment for the students. However, there are some drawbacks too; students may ignore the need to learn certain clinical skills such as medicolegal issues and using a holistic approach to assess patients. ${ }^{9}$

It is true that physicians are much too busy with clinical work to have the time to devote themselves to teaching skills at the bedside or at outpatient clinics. This obviously hampers the clinical competence of students. Clinical skill labs represent one solution to this problem. ${ }^{10}$ In addition, the use of simulators enables students to practice and make mistakes without any risk to patients or themselves. ${ }^{9}$ However, how a skill lab can help students in learning skills needs to be investigated through a longitudinal study, in which one follows many students from the time they join medical college till they become professional doctors. Moreover, further study is required to ensure that skill lab training during the preclinical years will help students perform better during their clinical years.

\section{Conclusion}

Students felt comfortable and were confident in showing their skill on dummies and manikins during the practical examination. Students' exam performance was improved after the skill lab training as compared with the conventional way of practical teaching methods. Therefore, the skill lab might help beginners to learn easily besides sharpening the skills of the professional personnel. Thus, in the preclinical years, students should be trained and exposed to the skill lab followed by hospital posting under the guidance of the supervisor. This innovative learning obviously creates a bridge between knowledge and practice of the students that will ultimately help them in their professional development.

\section{Acknowledgment}

I would like to thank Dr Shilu Thapa and Dr Suchen Kumar Yadav of Department of Physiology, Gandaki Medical College, for their help during the study.

\section{Disclosure}

The author reports no conflicts of interest in this work.

\section{References}

1. Skills Lab - National Centre for Health Profession Education (NCHPE) [homepage on the internet]. TU Institute of Medicine. [Updated 2011; cited 2016 Dec 8]. Available from: http://www.nchped.org.np/. Accessed December 8, 2016.

2. Tribhuvan University Institute of Medicine. Course title: Basic clinical Skills. Curriculum for Bachelor of Medicine and Bachelor of Surgery (MBBS). Maharajgung, Kathmandhu, Nepal: Medical Education Department; 2008:215.

3. Ali L, Nisar S, Ghassan A, Ali Khan S. Impact of clinical skill lab on students' learning in preclinical years. J Ayub Med Coll Abbottabad. 2011;23(4):114-117.

4. Junger J, Schafer S, Roth C, Schellberg D, Ben-David MF, Nikendei C. Effects of basic clinical skills training on objective structured clinical examination performance. Med Educ. 2005;39:1015-1020.

5. Augustin M. How to learn effectively in medical school: test yourself, learn actively, and repeat in intervals. Yale J Biol Med. 2014;87(2):207-212.

6. Shuid AN, Yaman MN, Abd Kadir RA, et al. Effect of early clinical skills teaching on 3rd year medical students' learning: the student perspective. J Taibah University Med Sci. 2015;10(1):26-32.

7. Bligh J. The clinical skills unit. Postgrad Med J. 1995;71:730-732.

8. Peeraer G, Scherpbier AJ, Remmen R, et al. Clinical skills training in a skills lab compared with skills training in internships: comparison of skills development curricula. Educ Health. 2007;20:125.

9. Abdulmohsen H. Al-Elq. Medicine and clinical skills laboratories. J Family Community Med. 2007;14(2):59-63.

10. Dhakal AK, Dhakal S. Clinical skills Lab: a need in Nepalese Medical School. J Patan Acad Health Sci. 2014;1(1):49-51.
Advances in Medical Education and Practice

\section{Publish your work in this journal}

Advances in Medical Education and Practice is an international, peerreviewed, open access journal that aims to present and publish research on Medical Education covering medical, dental, nursing and allied health care professional education. The journal covers undergraduate education, postgraduate training and continuing medical education

\section{Dovepress}

including emerging trends and innovative models linking education, research, and health care services. The manuscript management system is completely online and includes a very quick and fair peer-review system. Visit http://www.dovepress.com/testimonials.php to read real quotes from published authors. 